\title{
DEFINING AND PROMOTING PROFESSIONALISM
}

\section{Know When to Rock the Boat: How Faculty Rationalize Students' Behaviors}

\author{
Shiphra Ginsburg, MD, MEd ${ }^{1,4,6}$, Lorelei Lingard, PhD 2,4 , Glenn Regehr, $P h D^{3,4}$, and Kathryn \\ Underwood, $P h D^{4,5}$
}

\begin{abstract}
'Department of Medicine, Faculty of Medicine, University of Toronto, Toronto, ON, Canada; ${ }^{2}$ Department of Pediatrics, Faculty of Medicine, University of Toronto, Toronto, ON, Canada; ${ }^{3}$ Department of Surgery, Faculty of Medicine, University of Toronto, Toronto, ON, Canada; ${ }^{4}$ Wilson Centre for Research in Education, University Health Network, Faculty of Medicine, University of Toronto, Toronto, ON, Canada; ${ }^{5}$ Ontario Institute for Studies in Education, Faculty of Community Services, Ryerson University, Toronto, ON, Canada; ${ }^{6}$ Mount Sinai Hospital, Toronto, ON, Canada.
\end{abstract}

BACKGROUND: When faculty evaluate medical students' professionalism, they make judgments based on the observation of behaviors. However, we lack an understanding of why they feel certain behaviors are appropriate (or not).

OBJECTIVE: To explore faculty's reasoning around potential student behaviors in professionally challenging situations.

DESIGN: Guided interviews with faculty who were asked to respond to 5 videotaped scenarios depicting students in professionally challenging situations.

SUBJECTS: Purposive sample of 30 attending Internists and surgeons.

\begin{abstract}
APPROACH: Transcripts were analyzed using modified grounded theory to search for emerging themes and to attempt to validate a previous framework based on student responses.
\end{abstract}

RESULTS: Faculty's reasoning around behaviors were similar to students' and were categorized by three general themes: Imperatives (e.g., take care of patients, behave honestly, know your place), Affect (factors relating to a student's "gut instincts" or personality), or Implications (for the student, patients, and others). Several new themes emerged, including "know when to fudge the truth", "do what you're told", and "know when to step up to the plate". These new codes, along with a near ubiquitous reference to Affect, suggests that faculty feel students are responsible for knowing when (and how) to bend the rules. Potential reasons for this are discussed.

CONCLUSIONS: Although faculty are aware of the conflicts students face when encountering professional challenges, their reliance on students to "just know" what to do reflects the underlying complexity and ambiguity that surrounds decision making in these situations. To fully understand professional decisionmaking, we must acknowledge and address these issues from both students' and faculty's points of view.

This study was presented as an oral abstract at the Association of American Medical Colleges/Research in Medical Education Annual Meeting, October 2004, Boston MA.
KEY WORDS: professionalism; medical education; undergraduate education.

$\mathrm{J}$ Gen Intern Med 23(7):942-7

DOI: $10.1007 /$ s11606-007-0401-3

(C) Society of General Internal Medicine 2007

\section{INTRODUCTION}

Evaluating professionalism has become an important issue for medical educators, with the current trend focusing on observed behaviors and competencies to maximize reliability and validity. ${ }^{1,2}$ Although direct observation is clearly important, assessing behaviors in isolation is insufficient-evaluators must also consider the context in which behaviors occur, any values conflicts that may be present, and the resolution of the situation. ${ }^{3,4}$ It is clear that behaviors themselves are not always transparent indicators of "professionalism" and that the translation of abstracted principles into action is complex. ${ }^{4,5}$

Medical students' professionalism is primarily evaluated by faculty attendings, but little is known about how they think students should act. In a recent study, we found that attending physicians often disagree about what students should or should not do in challenging situations. Significant inconsistency existed between and even within individual faculty about what they considered to be appropriate medical student behavior in a given scenario. ${ }^{4}$ In an effort to move beyond the simple analysis of behaviors, some of our other work has examined students' reasoning in the face of professional dilemmas. This research demonstrated that when faced with challenging professional situations, students are motivated to act based not only on the principles of professionalism, but also on the basis of affect (or "self") issues, or potential implications of their actions. ${ }^{6}$ Knowing how students reason through these dilemmas provides important insights into how they make decisions about how to act when faced with these sorts of challenges. However, it is still not clear how faculty would reason through such dilemmas when considering how students should behave.

The purpose of this study was therefore to use videotaped scenarios of medical students in professionally challenging situations to explore and categorize faculty's reasoning around these potential student behaviors and to compare this with students' reasoning. 


\section{METHODS}

The subjects for this study were 30 faculty members from the Departments of Medicine and Surgery at the University of Toronto. Sample size was based on theoretical sampling, ${ }^{7}$ and our previous experience with this methodology and subject area. Potential subjects were attending physicians who spend at least 3 months per year on clinical service with medical students, thus forming a criterion-based, purposeful pool of subjects. After ethics approval was obtained, recruitment took place via e-mail with responses sent directly to a research assistant (RA) who was unknown to potential participants. Participation was anonymous, voluntary, and remunerated.

The scenarios used in this study were developed based on previous research, and further details on their development can be found elsewhere. ${ }^{6}$ Briefly, the scenarios represent real life situations as told to us by medical students, and were chosen to reflect a range of domains and contexts. Each is a videotaped dramatization of a student placed in a challenging situation that requires action on the part of the student. Each video ends at the point at which the student must act (see the Appendix for a description of the scenarios).

Individual, 1-hour, semistructured interviews were led by a trained RA. The videos were played in the same order for each participant. After each video, the participant was asked: What do you think the student should do next? What do you think a student should not do in this situation? Why or why not?

The interviews were audiotaped, transcribed, and rendered anonymous. Researchers were blinded as to the specialty of the participant (Medicine or Surgery).

\section{Analysis}

Our sample consisted of 30 subjects responding to 5 scenarios each. However, because of technical difficulties, 1 faculty's comments on scenario 1 were not captured. Content analysis was performed to catalogue the behaviors that faculty proposed, and the results of this have been published elsewhere. ${ }^{4}$ This paper focuses on the modified grounded theory analysis that was undertaken to understand the nature of faculty members' reasoning behind their suggested behaviors. ${ }^{8}$ Briefly, grounded theory is a methodology used to develop a "wellintegrated set of concepts that provide a theoretical explanation" of a phenomenon. ${ }^{8,9}$ In this study, a modified technique was used whereby we began with the set of themes developed from interviews with students in a previous study. ${ }^{6}$ A group of 2-3 researchers and a highly qualified RA began coding sequential transcripts with the previous framework, using a constant comparative technique in an iterative manner with the original codes being revised as new themes (or interpretations) emerged from the data. Analysis proceeded until the codes and new framework were stable. The RA then entered and coded all 30 transcripts using NVivo software. ${ }^{10}$ Coding was verified for accuracy by 1 researcher (SG).

\section{RESULTS}

Our initial sample included 3 pilot interviews, followed by interviews with 15 Medicine Faculty and 15 Surgical Faculty. Three interviews were lost in transcription, and the 3 pilot interviews were included (no changes had been made to the interview script or technique). Thus, the final sample consisted of 13 Medicine and 17 Surgery Faculty interviews, which resulted in 296 pages of text for analysis. No major differences were found between responses of the medical and surgical faculty, so participants are reported together and referred to simply as "Faculty".

As in our previous work, we analyzed the data by looking at the reasons faculty gave for suggesting student behaviors, which largely validated the student-generated framework. ${ }^{6}$ When faculty discussed the reasons for proposed student actions, they referenced Principles of professionalism, Affect (students' emotions, feelings or instincts) and potential Implications of actions (for patients, students and others), as seen in Table 1. Please note that although the validity of counting comments in qualitative research is controversial (it is not the number of instances that matters the most, it is the salience of the comments) numbers are provided in this case to illustrate the prevalence of these themes across the data set. No differences were found between the student and faculty frameworks in the Implications code; therefore, it will not be discussed further in this paper (data not shown). The evolution of the two other major codes is discussed below.

\section{Principles/Imperatives}

When explaining why certain actions were suggested, the students in our previous study referenced certain principles of professionalism, such as patient care, honesty, and duty to report. ${ }^{6}$ Consistent with the nature of the interview questions (i.e., what should the student do next?), faculty framed these

Table 1. Number of Interviews in Which Each Code Arose Along with the Total Number of Comments Across all Interviews and Scenarios

\begin{tabular}{|c|c|c|}
\hline $\begin{array}{l}\text { Thematic } \\
\text { category }\end{array}$ & $\begin{array}{l}\text { Number of } \\
\text { interviews in } \\
\text { which each } \\
\text { code arose } \\
(N=30)\end{array}$ & $\begin{array}{l}\text { Total number } \\
\text { of comments } \\
\text { captured } \\
\text { under each code } \\
\text { across all scenarios }\end{array}$ \\
\hline Imperative & 30 & 558 \\
\hline Take care of patient & 29 & 137 \\
\hline Provide appropriate care & 28 & 65 \\
\hline Provide comfort & 24 & 90 \\
\hline Behave honestly & 28 & 148 \\
\hline Disclose the truth & 26 & 77 \\
\hline Behave with Integrity & 20 & 48 \\
\hline Know when to "fudge" & 16 & 30 \\
\hline Report the bad eggs & 15 & 28 \\
\hline Use resources efficiently & 17 & 25 \\
\hline Get a good education & 21 & 56 \\
\hline Know your place & 30 & 178 \\
\hline Do what you're told & 25 & 68 \\
\hline Obey & 25 & 46 \\
\hline Defer & 12 & 22 \\
\hline Know your limits & 23 & 56 \\
\hline Step up to the plate & 28 & 64 \\
\hline Know the system & 23 & 62 \\
\hline Affect & 30 & 134 \\
\hline Implications & 30 & 263 \\
\hline For the patient & 29 & 96 \\
\hline For others & 26 & 63 \\
\hline For the student & 29 & 151 \\
\hline
\end{tabular}


principles as imperatives (i.e., "students should") and additionally described some alternative interpretations in several cases, as seen in Figure 1. For example, the principles of Disclosure and Honesty merged into the imperative to "Behave honestly"; this category was further subdivided into imperatives to "Disclose the truth", "Behave with integrity" and also "Know when to fudge the truth". The principles of Obedience, Deference, and Allegiance to one's team merged into the imperative to "Know your place"; this was further subdivided into the imperatives to "Do what you're told" ("Obey" or "Defer"), "Know your limits", and also "Know when to step up to the plate". The significance of these changes will be described below.

"Behave honestly". In some cases, the meaning of "behave honestly" was straightforward; for example, in response to Video 1 in the Appendix one subject stated that "The patient, you know, has a right to know their test result" [F6]. Another said, "Keeping ... information from [the patient] is absolutely insane" [F27]. Similarly, behaving with integrity appeared to be a simple concept, as one subject stated in response to Video 3 in the Appendix: "She's made a commitment to that patient, to talk to him before rounds. She should honour her commitment".

However, consider the following example in response to Video 1 in the Appendix: “...we don't lie to our patients [and] say whatever makes them happy... we may minimize the truth, but we still tell them the truth, and this is something that I think at [the students' level] I would expect her to do" [F2]. This idea of minimizing or otherwise "fudging" the truth was a strategy not espoused by students in our previous study; indeed, the occasional student that mentioned it only did so for the explicit purpose of rejecting it outright as a legitimate response. Faculty, however, explicitly discussed this concept as a strategy and even described some different ways in which a student might fudge the truth, for example, "You know, you can sort of sugar coat the truth a bit, but you should never lie" [F20]. Another stated that the student should answer the patient by "neither completely saying the truth but not completely lying either" [F10]. One offered further advice: "She could be truthful; she could lie, which is not an option. Or she should evade. ... I'm a big fan of evasion. I think it's a very useful tactic sometimes. Um, but only in certain situations" [F13]. What is not directly articulated by faculty, however, is how students are supposed to know when (and how) to fudge the truth.

"Know Your Place". In our student interviews, a prominent theme emerged that related to obeying or deferring to one's supervisors. We were not surprised to see faculty discuss the importance of deferring to someone who might know more than the student, as in response to scenario 2, where F6 states that the student "can follow the resident's advice, because ...

\section{Student Generated Principles}

\begin{tabular}{|l|l|}
\hline Patient care/take care of patient \\
\hline Patient comfort/relieve anxiety \\
\hline Disclosure
\end{tabular}

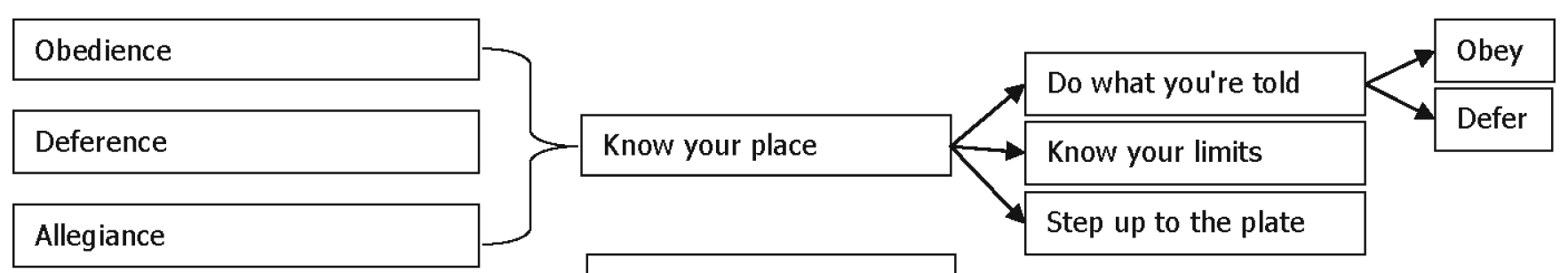

Know the system

Fig. 1. Evolution of student generated principles ${ }^{6}$ into faculty generated imperatives 
he doesn't know. The resident might be right". However, we also saw numerous examples of faculty suggesting that students should blindly obey. Consider F13's response: "[The student] should take the advice he's given and forget about it. If the clerk were to disregard this advice that would be very bad clerkship behaviour". Another said: "I don't think [the student] has any choice here. It's not his position to challenge. What's he going to do?" [F2].

Other responses indicated that a student should also know his or her limits when deciding how to act. For example, "[The patient] needs diabetic teaching. ... The student should not even attempt to go into that, because he doesn't know enough" [F7]. Another stated that "You know, eventually you'll be at that level, and maybe there are certain decisions that you can make, but those are the decisions that are within your level of training, and you should fully understand your limitations as a medical student" [F29].

This suggests that from the faculty point of view, what's best for students is to do what they're told, either because they were told or because they should know their own limits. However, faculty did not consistently feel this way. Consider some of the alternative responses given to the same scenario: "[The student] should follow up because it's his patient. I think he has a duty. The resident obviously had a duty, but he shirked that responsibility for now, and um... the student needs to go and make sure the patient's well cared for." [F2]; or "Although the resident has abdicated his role as a professional, the student can't abdicate his just to follow suit" [F12]. In these instances, the faculty felt that the student's job was to step up to the plate and cover for others. Another subject stated it even more succinctly: "There comes a time where you follow orders and there comes a time when you don't follow orders" [F14]. Again, this suggests that it is up to the students, although the criteria for deciding when are left tacit.

\section{Affect}

This category was developed in the previous data set to capture those instances in which emotions, feelings, or instincts drove students' consideration of an action. ${ }^{6}$ In this data set, Affect was not only present, it emerged as a surprisingly dominant theme, being referred to in every interview with a total of 134 comments. Moreover, faculty framed Affect in a number of ways, focusing on students' beliefs, gut instincts, or personality. For example in scenario 1, one faculty, discussing whether or not the student should tell the patient the test result, stated "It depends on what their personal beliefs are" [F4]. In scenario 2, another faculty stated that a student should go "with [his] instincts, uh... like you know, if you sense a level of discomfort in yourself, don't just ignore it" [F6]. Still others framed it as a personality issue, as in the following: "[The most likely thing a student would do] would depend entirely on whether the student was passive, passiveaggressive, active-aggressive [laughs]. It would depend entirely on the personality of the student, I think" [F29]. This reinforces the sense that the right thing to do in a situation is dependent on the student himself/herself.

\section{DISCUSSION}

This study explored the opinions of Medicine and Surgery faculty members regarding potential medical student behav- iors in professionally challenging situations. The scenarios and methodology used in this study were identical to those used in earlier work with medical students, and largely validated our previously developed theoretical framework. ${ }^{6}$ Faculty members recognized the scenarios as authentic dilemmas for medical students, and were sensitive to the difficulties students' face. When explaining why a particular behavior was suggested, they referenced the same general principles that the students did, such as honesty and self-regulation. However, there were some key differences in the way these principles were framed and interpreted.

Students made reference to the principles of honesty and disclosure. Faculty framed these as the imperative to behave honestly, which included disclosing the truth and behaving with integrity. But they additionally thought students should know when (and how) to fudge the truth. And while students and faculty agreed that there were times that students should do what they are told, faculty additionally thought students should know when to disobey and step up to the plate. These alternative interpretations reflect flexibility in the definition and application of the principles of professionalism. We have previously shown that faculty attendings often disagree about what students should or should not do in challenging situations; this data suggests that they also have disparate opinions regarding why they think students should or should not act.

One theme that was surprisingly prominent in faculty's responses concerned a reliance on medical students to figure things out for themselves. Faculty suggested that students should not only know the rules but should also know when to bend them. As one put it, "You should be mature enough to know when to push ahead and when to not push ahead. When to rock the boat and when not to rock the boat. You know?" [F28]. We previously showed that medical students are sometimes motivated to act based on what we termed "affect" or selfissues. We expected this category to become marginalized or even disappear in the current study, as it is one thing for a student to say "I would go with my gut instinct" but quite another for a faculty attending to say that what a student should do is go with her gut instinct. We did not expect that faculty would consider that how a student might feel in the moment would be a legitimate reason for action. Moreover, this concept does not appear on any of the usual frameworks for professionalism. However, we found that Affect was not only present, it was ubiquitous.

These findings suggest that from faculty's point of view, students are expected to know when to fudge the truth, when to step up to the plate, and when to go with their gut instincts. There are several potential explanations for this reliance on medical students to simply know what is right or to figure things out on their own. One possibility is that faculty may be reluctant to directly address these issues themselves. Faculty have been previously shown to give direct feedback only rarely to residents who display unprofessional behavior; instead, responses are usually indirect, nonverbal, and often misinterpreted. ${ }^{3,11}$ Faculty's discomfort in dealing with professional dilemmas can be explained, at least in part, by a perceived lack of training and expertise in the area, a lack of time and institutional support to give proper corrective feedback, a fear of repercussions, and a relative underemphasis on nonclinical matters on the wards. But there are other reasons why this phenomenon may be occurring. 
Definitions of professionalism tend to be based on abstracted ideals, such as honesty or altruism; and there is often a gap between how these ideals are expressed formally and how they are experienced in practice. ${ }^{12}$ As we have previously written, these definitions tend to describe the idealized or consummate professional with little room for mistakes. ${ }^{3}$ Furthermore, evaluation forms are usually phrased in a way that does not allow room for concepts such as "fudging the truth". Instead, if a student is seen to lie, and a faculty member is required to evaluate that student, the behavior should technically be recorded as a lapse in honesty and would therefore be considered unprofessional-although we know that fudging the truth, in the right context with the right values conflicts present, is sometimes considered to be the optimal behavior.

Given the above, it is perhaps not difficult to see why faculty respond as they do when asked how and why students should act in challenging situations. It might be very difficult for them to justify to students (or even themselves) that sometimes it is okay to lie to a patient or circumvent a resident's order when these are not avowed in the formal curriculum. Not to mention how they might teach students that sometimes the right thing to do is to go with their beliefs or gut instincts, or that their personality should dictate the correct behavior. These are certainly not espoused by the profession as being legitimate reasons for action, and they do not appear on standard evaluation forms for professionalism. Faculty would undoubtedly find it easier to evade the issue and place the onus on students to navigate their own way, hoping they would figure out the "right" thing to do.

At some point, however, given the nature of medical education, faculty members do have to evaluate students' professionalism, and it is not yet clear how they form these judgments. With the current focus on direct observation and evaluation of behaviors, it is not surprising that faculty direct their attention to the behaviors students display, assuming that these behaviors reflect appropriate professional attitudes and values. But the relationship between attitudes and behaviors is complex and indirect. As Rees et al. recently wrote, people generally act in accordance with their attitudes, but this is subject to much external influence-including social pressure (and the fact that students are being observed and evaluated) and the degree of difficulty required to enact the behavior. ${ }^{5}$ When external pressure is high and the behavior is difficult-as in the scenarios in this study-an individual's attitudes account for only a small fraction of variance in observed behavior. ${ }^{13}$ The authors then ask which student we should worry about more-the one who does the "right" thing but for unknown or questionable reasons or the one who demonstrates a lapse in professionalism when attempting to act on exemplary reasons? That is, if we can even agree on what we mean by "right". Which student would be considered to be "more professional"? It seems clear that faculty should (and probably do, at least to some extent) consider both elements-behaviors and the reasons behind them-when making their judgments. But the issue of how these elements are weighted or reconciled in a real life situation has not been clarified. In some instances, the behavior enacted might carry the most weight, but we have also shown that in many cases, the perceived motivation behind the behavior is what influences judgment. ${ }^{14}$ These questions are being addressed in ongoing studies.
These results might also be taken as yet another illustration of how the hidden curriculum is expressed. ${ }^{15,16}$ Students are taught one framework but experience another: behave honestly, but sometimes fudge the truth; do what you're told, but sometimes step up to the plate. But perhaps more interesting from a conceptual point of view is the finding that faculty may be just as conflicted as their students - they do not just perpetuate, they are also affected by the hidden and disavowed curricula, as can be seen by the following faculty's response when asked what a student should not do in scenario 4: "She's totally screwed. She... what she shouldn't have done is what she did, which is just to go ahead and examine the patient, but what choice did she really have? You know, she could have refused, but a third year student is very vulnerable, and she might not have felt comfortable doing that. So I don't think there was a wrong course of action. I think every course for her was wrong, but it wasn't her fault. She was put in a very bad situation" [F6]. This illustrates that the dilemma exists not only from the student's point of view, but from the faculty's as well-the student has been put in a "very bad situation", but in a way, so has the faculty who has to teach and evaluate her.

It is therefore important to recognize that faculty's reliance on medical students to just "know" what is right is not the result of laziness or a lack of knowledge about professionalism on their part-it reflects the underlying complexity and ambiguity that surrounds decision making in professionally challenging situations. We are not suggesting that faculty should disregard the formal curriculum or that students should be taught how to lie. But our results suggest that we are doing a disservice to students and faculty by ignoring these incongruities. Some authors have studied the implementation of various interventions to help mitigate these effects, such as "ward ethics" sessions, debriefings, and reflective writing with varying degrees of success. ${ }^{17,18}$ These studies confirm that without an acknowledgment of the difficulties inherent in these sorts of dilemmas from both points of view, a full understanding of professional decision-making will not be possible.

Acknowledgments: This study was funded by a research grant from the Medical Council of Canada. Additional support was provided by the Wilson Centre for Research in Education, University of Toronto. Lorelei Lingard is supported by a CIHR New Investigators Award and as the BMO Financial Group Professor in Health Professions Education Research. Glenn Regehr is supported as the Richard and Elizabeth Currie Chair in Health Professions Education Research.

Conflicts of Interest: No author has any conflict of interest.

Corresponding Author: Shiphra Ginsburg, MD, MEd;, Mount Sinai Hospital, 433-600 University Ave, Toronto, ON, Canada M5G 1X5 (e-mail: shiphra.ginsburg@utoronto.ca).

\section{APPENDIX}

\section{Brief Summaries of Videos}

Descriptions of videotaped scenarios used as prompts for faculty reasoning.

Video 1. A student has just been told by the attending surgeon not to tell a patient the results of a test showing that she has a 
tumor; in the next scene, the patient asks the student directly what her tests show.

Video 2. A medical resident is trying to get the team out early on the last day of a rotation, but a student wants the resident to review a patient's insulin orders first. The resident says they can wait until Monday, but the student is uncomfortable.

Video 3. A student wants to go watch a bone marrow biopsy, but has just told a patient with dementia that she'd see him right now.

Video 4. A male doctor in a fertility clinic is enthusiastically teaching his students how to examine a male patient's genitals, but the patient has not been asked permission and is uncomfortable. The attending asks the female student to palpate and explain what she feels, but no one is wearing gloves.

Video 5. A student is doing her first thoracentesis while the resident supervises, when a nurse walks in and asks the student if she's ever done one before.

\section{REFERENCES}

1. Arnold L. Assessing professional behaviour: yesterday, today, and tomorrow. Acad Med. 2002;77(6):502-15.

2. Stern DT, ed. Measuring Medical Professionalism, 1st Edn. New York, NY: Oxford University Press: 2006

3. Ginsburg S, Regehr G, Hatala R, et al. Context, conflict, and resolution a new conceptual framework for evaluating professionalism. Acad Med 2000;10;75(10 Suppl):S6-11.
4. Ginsburg S, Regehr G, Lingard L. Basing the evaluation of professionalism on observable behaviours: a cautionary tale. Acad Med. 2004;79 (10 Suppl):S1-4.

5. Rees CE, Knight LV. Viewpoint: the trouble with assessing students' professionalism: theoretical insights from sociocognitive psychology. Acad Med. 2007;82(1):46-50.

6. Ginsburg S, Regehr G, Lingard L. The disavowed curriculum: understanding students' reasoning in professionally challenging situations. J Gen Intern Med. 2003;18(12):1015-22.

7. Creswell JW. Data collection. In: Creswell JW, ed. Qualitative Inquiry and Research Design: Choosing Among Five Traditions. Thousand Oaks, CA: Sage; 1998:109-35.

8. Glaser BG. Basics of Grounded Theory Analysis. Mill Valley, CA: Sociology Press: 1992.

9. Kennedy TJ, Lingard L. Making sense of grounded theory in medical education. Med Educ. 2006;40(2):101-8.

10. NVivo qualitative data analysis program. Version 2.0. QSR International Pty Ltd.; 2002.

11. Burack JH, Irby DM, Carline JD, Root RK, Larson EB. Teaching compassion and respect: attending physicians' responses to problematic behaviours. J Gen Intern Med. 1999;14(1):49-55.

12. Ginsburg S, Regehr G, Stern DT, Lingard L. The anatomy of the professional lapse: bridging the gap between traditional frameworks and students' perceptions. Acad Med. 2002;77(6):516-22

13. Wallace DS, Paulson RM, Lord CG, Bond CF. Which behaviours do attitudes predict? Meta-analyzing the effects of social pressure and perceived difficulty. Rev Gen Psychol. 2005;9(3):214-27.

14. Lavine E, Regehr G, Garwood K, Ginsburg S. The role of attribution to clerk factors and contextual factors in supervisors' perceptions of clerks' behaviours. Teach Learn Med. 2004;16(4):403-8.

15. Hafferty FW, Franks R. The hidden curriculum, ethics teaching, and the structure of medical education. Acad Med. 1994;69(11):861-71.

16. Stern DT. Practicing what we preach? an analysis of the curriculum of values in medical education. Am J Med. 1998;104(6):569-75.

17. Fryer-Edwards $\mathbf{K}$, Wilkins $\mathbf{M D}$, Baernstein A, Braddock $\mathbf{C H}$. Bringing ethics education to the clinical years: ward ethics sessions at the University of Washington. Acad Med. 2006;81(7):626-31.

18. Baernstein A, Fryer-Edwards K. Promoting reflection on professionalism: a comparison trial of educational interventions for medical students. Acad Med. 2003;78(7):742-7. 